\section{Sock-line hyperpigmentation in infancy}

We present a 4-month-old healthy male infant of Asian/ Mediterranean origin with partially circumferential hyperpigmented bands on the lower legs.

The appearance of these marks led his health visitor to be concerned about the possibility of non-accidental injury. He was referred to the local paediatric unit and admitted for investigations, including a skeletal survey.

Two weeks before, the elastic of a new pair of socks had led to red circumferential marks at exactly the same site (figure 1). These erythematous marks evolved into the hyperpigmented bands seen by his health visitor. The marks (figure 2) corresponded precisely with the site of compression by the elastic of his socks.

There have been several published reports of sock-line hyperpigmentation in Caucasian, Asian and African-American infants. ${ }^{1}$ Variants of this phenomenon include mitten bands and heel-line hyperpigmentation from heel-length socks. Bands may be single or multiple, unilateral or bilateral and palpable or impalpable. Three reported cases were biopsied, which demonstrated postinflammatory hyperpigmentation ${ }^{2}$ and lentiginous melanocytic hyperplasia. ${ }^{3}$

The aetiology is not clearly understood, but it is thought to relate to dermal inflammation or panniculitis caused by sustained compression, resulting in postinflammatory hyperpigmentation.

Sock-like bands typically resolve within a few months, although persistence after 2-5 years has been reported. ${ }^{1}{ }^{4}$

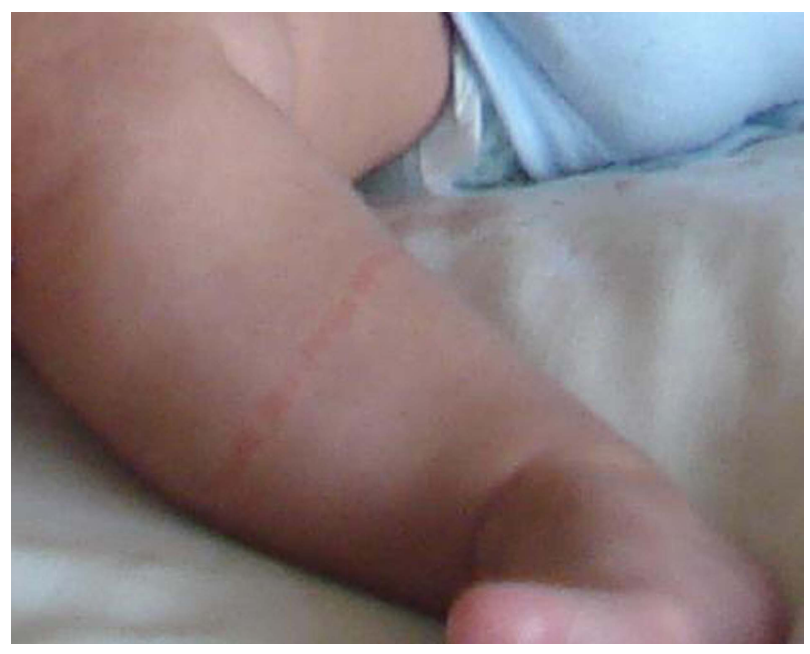

Figure 1 Acute curvilinear band (parental photograph).

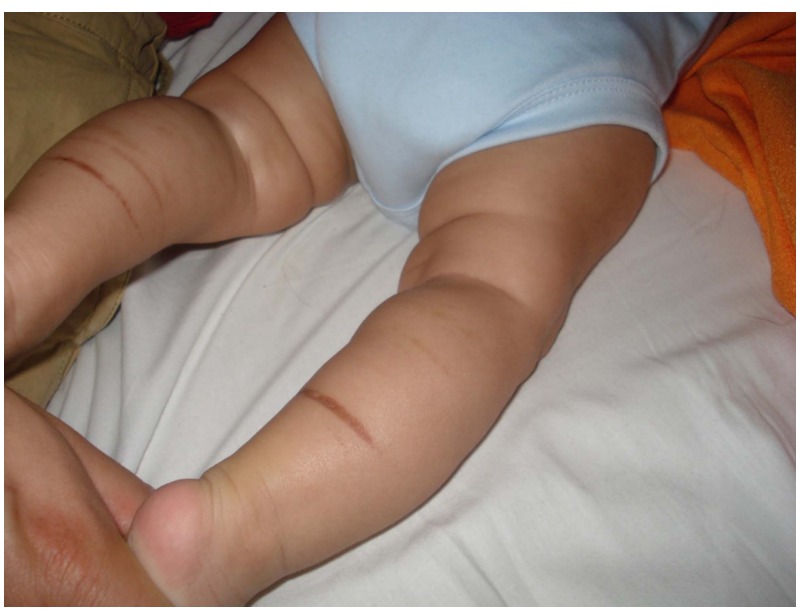

Figure 2 Postinflammatory hyperpigmented bands.

It is important to recognise this condition and to distinguish it from non-accidental injury with ligatures. Although it is not possible to predict which infants are most at risk, it is prudent to advise parents to avoid excessively tight socks and mittens.

\section{Karina Forde, Mary Glover}

Great Ormond Street Hospital for Children, London, UK

Correspondence to Dr Karina Forde, Great Ormond Street Hospital for Children, Level 6 Southwood Building, Great Ormond Street, London WC1N 3JH, UK; karina.forde@gosh.nhs.uk

Contributors MG, Consultant Paediatric Dermatologist, edited the final article draft before submission.

Competing interests None.

Patient consent Obtained.

Provenance and peer review Not commissioned; internally peer reviewed.

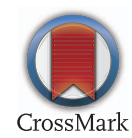

To cite Forde K, Glover M. Arch Dis Child 2015;100:532

Accepted 10 December 2014

Published Online First 30 December 2014

Arch Dis Child 2015;100:532. doi:10.1136/archdischild-2014-307591

\section{REFERENCES}

1 Berk DR, Baylliss SJ. Mitten-line hyperpigmentation: a reactive process analogous to sock-line hyperpigmentation. Pediatr Dermatol 2010;27:401-2.

2 Berk DR, Tapia B, Lind A, et al. Sock-line hyperpigmentation: case series and literature review. Arch Dermatol 2007;143:428-30.

3 Zhu YI, Fitzpatrick JE, Weston WL. Congenital curvilinear palpable hyperpigmentation. J Am Acad Dermatol 2005;53:S162-4.

4 Marque MM, Guillot B, Le Gallic G, et al. Raised limb bands in infancy; a post-traumatic aetiology?. Br J Dermatol 2007;24:391-3. 